\title{
Comments on 'A comparative study of ANN and neuro-fuzzy for the prediction of dynamic constant of rockmass'
}

\author{
by T N Singh, R Kanchan, A K Verma and K Saigal \\ (J. Earth Syst. Sci., 114, February 2005, 75-86) \\ TARKAN Erdik and ZeKai ŞEN \\ Istanbul Technical University, Faculty of Civil Engineering, Hydraulics and Water \\ Resources Division, Maslak 34469, Istanbul, Turkey.
}

Singh et al (2005) examined the potential of the ANN and neuro-fuzzy systems application for the prediction of dynamic constant of rockmass. However, the model proposed by them has some drawbacks according to fuzzy logic principles. This discussion will focus on the main fuzzy logic principles which authors and potential readers should take into consideration.

We wish to thank the authors of 'A comparative study of ANN and neuro-fuzzy for the prediction of dynamic constant of rockmass' for examining the potential of the ANN and neuro-fuzzy systems application for prediction of dynamic constant of rock-mass. We would like to present the following important points of view, which the authors and potential researchers need to consider. This discussion will focus on six main points that are not considered in the study.

\section{Comment 1}

Singh et al (2005) did not provide the necessary minimum information about the working mechanism of ANN and its related constituents. It is not clear which transfer functions are used between input and hidden layers or hidden and output layers in the proposed ANN model? The authors also did not define "wij", "wjk" in their figure 1.

\section{Comment 2}

Singh et al (2005) did not indicate any knowledge about their preference for the Gaussian membership function (MF) out of triangle, trapezoidal, or bell shaped MFs in their neuro-fuzzy model. Is it due to the fact that the Gaussian MFs are useful for better modeling nonlinear and smooth trends with continuous derivatives as they are used in this study?

\section{Comment 3}

Using "the correlation coefficient" as numerical error criteria requires Gaussian (normal) probability distribution of the variables. It is, therefore, necessary to check the normality of data if such a formulation is to be used for comparison. The authors failed to consider this point.

\section{Comment 4}

The application of ANN modeling is often achieved without fundamental physical reasoning as an input-output data matching. However, fuzzy logic (FL) modeling requires insight into the physical configuration of the concerned input and output variables in terms of MFs and their connections through fuzzy rule basis, especially with ANFIS program in MATLAB software after the training phase. Otherwise, misinterpretations, misuses

Keywords. $p$-wave velocity; neuro-fuzzy; artificial neural network; compressive strength; density; hardness. 

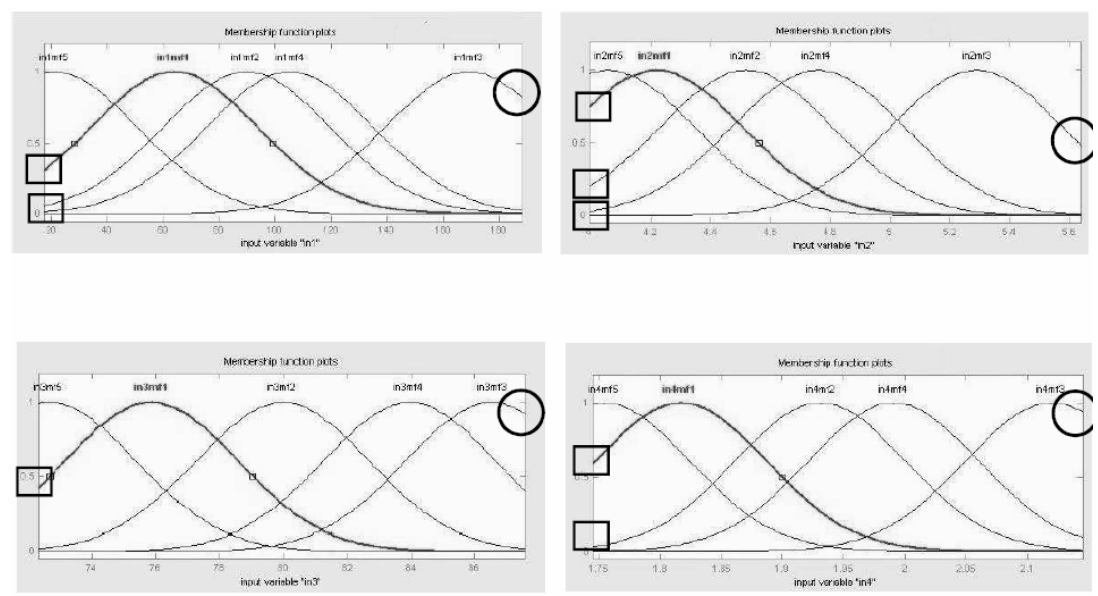

and flaws might be encountered in many internationally published papers (Şen 2006, 2007; Erdik 2008a, b, c, d, e). In order to avoid such pitfalls it is necessary to concentrate on the basic philosophy of FL rather than its mechanical uses without logical reasoning and interpretations. Basic FL principles require that the most left and right MFs should have membership degree (MD) equal to 1 (Şen 2004, 2006, 2007; Erdik and Sen 2008). However, the right-most MFs, namely "in1mf3", "in2mf3", "in3mf3" and "in4mf3", encircled in continuous circles in their figure 3 above, are decreasing limbs towards "high" values, which are exactly contrary to the FL principle. Therefore, these MFs, produced after the training process, are erroneous, linguistically. The right limb of the right most fuzzy set should either reach $1 \mathrm{MD}$ or there should be another fuzzy set with the limb at the right, reaching $1 \mathrm{MD}$.

\section{Comment 5}

In FL philosophy, MDs, rectangular blocked in their figure 3 above, should be either " 1 " or "0" or there should be explanations for such cases which are missing in the current paper.

\section{Comment 6}

Both MFs "in1mf2" and "in1mf4" and "in2mf5" and "in2mf1" for the input variables "in1" and "in2", respectively in their figure 3 above, are neither physically nor logically plausible. Because, these MFs are nearly equivalent (geometrically very close to each other), indicating that the same set of data portion is attached with two different fuzzy sets, which cannot be acceptable according to the basic principles of FL methodology. Therefore, in order to economize the model authors should have trained the model with less MFs for the "in1" and "in2", respectively.

\section{References}

Erdik T 2008a Discussion on "Prediction of ground vibrations resulting from the blasting operations in an open-pit mine by adaptive neuro-fuzzy inference system"; Environ. Geol. doi: 10.1007/s00254-008-1321-1.

Erdik T 2008b Discussion on "Prediction of concrete elastic modulus using adaptive neurofuzzy inference system"; Civil Engineering and Environmental Systems, doi: $10.1080 / 10286600802057597$.

Erdik T 2008c Discussion on "A wavelet-neuro-fuzzy combined approach for digital relaying of transmission line faults"; Electric Power Components and Systems 36(12) December 2008.

Erdik T 2008d Fuzzy Logic approach to Conventional rubble mound structures design; Expert Systems with Applications (in press).

Erdik T 2008e Discussion on "Prediction of mechanical properties of recycled aggregate concretes containing silica fume using artificial neural networks and fuzzy logic; Comput. Mater. Sci., doi:10.1016/ j.commatsci.2008.06.004

Erdik T and Sen Z 2008 Discussion on "Hybrid soft computing approach for mining of complex construction databases"; ASCE Journal of Computing in Civil Engineering (in press).

Şen Z 2004 Fuzzy Logic and system models in water sciences, Turkish Water Foundation, Istanbul.

Şen Z 2006 Discussion on "Applying fuzzy theory and genetic algorithm to interpolate precipitation"; J. Hydrol. 331 360-363.

Şen Z 2007 Discussion on "Takagi-Sugeno fuzzy inference system for modeling stagedischarge relationship"; J. Hydrol. 337 242-243.

Singh T N, Kanchan R K, Verma A K and Saigal K 2005 A comparative study of ANN and neuro-fuzzy for the prediction of dynamic constant of rockmass; J. Earth Syst. Sci. 114(1) 75-86. 